\title{
Cholesterol metabolism and serum non-cholesterol sterols: summary of 13 plant stanol ester interventions
}

\author{
Maarit Hallikainen ${ }^{1}$, Piia Simonen ${ }^{2}$ and Helena Gylling ${ }^{1,3^{*}}$
}

\begin{abstract}
Background: The efficacy and safety of plant stanols added to food products as serum cholesterol lowering agents have been demonstrated convincingly, but their effects on cholesterol metabolism and on serum non-cholesterol sterols is less evaluated. The aim of this study was to assess the validity of serum non-cholesterol sterols and squalene as bioindices of cholesterol synthesis and absorption, and to examine how the individual serum non-cholesterol sterols respond to consumption of plant stanols.

Methods: We collected all randomized, controlled plant stanol ester (STAEST) interventions in which serum cholestanol, plant sterols campesterol and sitosterol, and at least two serum cholesterol precursors had been analysed. According to these criteria, there was a total of 13 studies (total 868 subjects without lipid-lowering medication; plant stanol doses varied from 0.8 to $8.8 \mathrm{~g} / \mathrm{d}$ added in esterified form; the duration of the studies varied from 4 to 52 weeks). Serum non-cholesterol sterols were assayed with gas-liquid chromatography, cholesterol synthesis with the sterol balance technique, and fractional cholesterol absorption with the dual continuous isotope feeding method.

Results: The results demonstrated that during the control and the STAEST periods, the serum plant sterol/ cholesterol- and the cholestanol/cholesterol-ratios reflected fractional cholesterol absorption, and the precursor sterol/cholesterol-ratios reflected cholesterol synthesis. Plant sterol levels were dose-dependently reduced by STAEST so that $2 \mathrm{~g}$ of plant stanols reduced serum campesterol/cholesterol-ratio on average by $32 \%$. Serum cholestanol/cholesterol-ratio was reduced less frequently than those of the plant sterols by STAEST, and the cholesterol precursor sterol ratios did not change consistently in the individual studies emphasizing the importance of monitoring more than one surrogate serum marker.
\end{abstract}

Conclusions: Serum non-cholesterol sterols are valid markers of cholesterol absorption and synthesis even during cholesterol absorption inhibition with STAEST. Serum plant sterol concentrations decrease dose-dependently in response to plant stanols suggesting that the higher the plant stanol dose, the more cholesterol absorption is inhibited and the greater the reduction in LDL cholesterol level is that can be achieved.

Trial registration: Clinical Trials Register \# NCT00698256 [Eur J Nutr 2010, 49:111-117]

Keywords: LDL cholesterol, Cholesterol absorption, Cholesterol synthesis, Cholestanol, Campesterol, Sitosterol, Lathosterol, Desmosterol, Squalene

\footnotetext{
* Correspondence: Helena.Gylling@hus.fi

${ }^{1}$ Institute of Public Health and Clinical Nutrition, Department of Clinical

Nutrition, University of Eastern Finland, Kuopio, Finland

${ }^{3}$ Department of Medicine, Division of Internal Medicine, University of

Helsinki, Helsinki, Finland, P.O. BOX 700 FIN-00029 HUS, Finland

Full list of author information is available at the end of the article
} 


\section{Background}

The hypocholesterolemic effect of dietary plant sterol supplementation was demonstrated for the first time in humans in the 1950's [1] and that of plant stanols in the 1980's [2]. Today, several food products with added plant sterols and plant stanols are used worldwide as a dietary means to lower serum total and LDL cholesterol concentrations by interfering with cholesterol absorption $[3,4]$. Thus, in addition to the reduction in the serum cholesterol concentration, these agents makes it possible to evaluate cholesterol metabolism in response to inhibition of cholesterol absorption.

The assessment of cholesterol absorption and synthesis is laborious in clinical studies. For this reason, serum non-cholesterol sterols have been examined as relative markers of whole-body cholesterol metabolism under steady state conditions with subjects consuming a normal habitual diet. The levels of serum cholesterol precursors (squalene, cholestenol, desmosterol, and lathosterol) reflect the activity of cholesterol synthesis, and serum plant sterols (campesterol and sitosterol), and cholestanol, reflect the absorption efficiency of cholesterol. Their validity has been assessed by comparing the synthesis marker values with those obtained with the sterol balance technique [5-11] or with the evaluation of hepatic 3-hydroxy-3-methyl-glutaryl-CoA reductase activity [12], and the absorption marker values have been validated with those obtained with continuous peroral or peroral-intravenous isotopes and tracers $[6-9,13,14]$. For particular, the cholesterol-standardized ratios of the relevant serum markers were best associated with cholesterol synthesis and absorption efficiency [6-9], and the absorption marker/synthesis marker ratios with wholebody cholesterol metabolism [6,7]. However, especially during interventions and when only one serum marker has been used, there have been inconsistencies in the results between the serum markers and absolute methods $[8,11]$. In a recent cross-sectional study, e.g., serum plant sterol/cholesterol-ratios did not correlate with fractional cholesterol absorption [15]. In this study, the study population of 175 hypercholesterolemic subjects was divided into those with the lowest and highest campesterol/cholesterol ratio, and cholesterol absorption efficiency was measured with a single oral-intravenous dose. Cholesterol absorption efficiency did not differ between the groups. Of special interest was the very low values of cholesterol absorption efficiency with a mean of $24 \%$, and only a few subjects reached the value of $50 \%$, which is considered the average mean value among different populations. The results were discussed by Grundy [16] that there may be methodological reasons related to the tracer or the single dose-method per se causing these particularly low cholesterol absorption values, which could explain the lack of association. To this end, the aim of this study was to assess the validity of the cholesterol absorption and synthesis markers during consumption of plant stanol-supplemented food products. We also examined the changes in cholesterol metabolism occurring in response to plant stanol interventions. Since in general the number of subjects in single plant stanol interventions has been somewhat limited, we gathered together from PubMed all randomized controlled studies in adults, in which at least two serum synthesis markers, two serum plant sterols, and serum cholestanol levels were analysed during plant stanol intervention.

\section{Methods}

\section{Study population}

With these criteria, 13 studies could be identified. These included 868 subjects (414 men and 454 women) with an age range from 20 to 73 years (Table 1). In eleven of the studies, the subjects had mild to moderate hypercholesterolemia [17-27]. In one study, the subjects were type 1 diabetics [28], and another study focused on type 2 diabetics [29]. All subjects were without lipid-lowering medication. The plant stanol dose varied from 0.8 to $8.8 \mathrm{~g} / \mathrm{d}$, and in all of the studies, the plant stanols were consumed as their fatty acid esters. Two of the studies were dose-response studies [23,27]. Six studies had a cross-over and seven employed a parallel design. The duration of plant stanol ester (STAEST) consumption varied from 4 to 52 weeks.

All subjects gave their written informed consent. All studies were performed according to the principles of the Declaration of Helsinki. The Ethics Committees of the University of Helsinki, Second Department of Medicine (studies in ref $19,20,21,26,27,29)$, University of Kuopio (studies in ref 17,22,23,24,28), the North Karelia Central Hospital (study in ref 18), and Joint Ethics Committee of the University of Turku and Turku University Central Hospital (study in ref 25) had approved the study protocols.

\section{Measurements}

Serum concentrations of non-cholesterol sterols were quantified from non-saponifiable serum-based materials by capillary gas-liquid chromatography (GLC) (Agilent 6890 N Network GC System, Agilent Technologies, Wilmington, DE) equipped with a $50 \mathrm{~m}$ long non-polar Ultra 2 capillary column (5\% phenyl-methyl siloxane; Agilent Technologies, Wilmington, DE) with $5 \alpha$-cholestane as internal standard [30]. Typical CVs at relevant concentrations were: cholesterol 3.2\%, cholestanol 2.7\%, desmosterol $6.0 \%$, lathosterol $3.7 \%$, campesterol $1.8 \%$, and sitosterol 2.4\%. Serum non-cholesterol sterols are given as concentrations $(\mu \mathrm{g} / \mathrm{dl})$ and in terms of ratios to 
Table 1 LDL cholesterol and serum non-cholesterol sterol/cholesterol-ratios in different studies during STAEST consumption

\begin{tabular}{|c|c|c|c|c|c|c|c|c|c|c|c|c|}
\hline \multirow[b]{2}{*}{ Reference } & \multirow[b]{2}{*}{ Design } & \multirow[b]{2}{*}{$\mathbf{N}$} & \multirow[b]{2}{*}{ Dose $(g / d)$} & \multirow[b]{2}{*}{ Duration (wk) } & \multicolumn{8}{|c|}{ First value: mean control value. In parenthesis: net relative change between STAEST and control values } \\
\hline & & & & & LDL-C & Cholestanol & Campesterol & Sitosterol & Squalene & Cholestenol & Desmosterol & Lathosterol \\
\hline Ref [18] & Parallel & 189 & 2 & 52 & $3.9(-8 \%)$ & $152(-5 \%)$ & $301(-35 \%)$ & $156(-37 \%)$ & $16(-1 \%)$ & $21(7 \%)$ & 81 (7\%) & $121(7 \%)$ \\
\hline $\operatorname{Ref}[24]$ & Crossover & 34 & 2 & 4 & $4.2(-13 \%)$ & $136(-4 \%)$ & $388(-\mathbf{2 8 \%})$ & $172(-\mathbf{2 9 \%})$ & 33 (22\%) & 16 (23\%) & 61 (11\%) & 164 (20\%) \\
\hline $\operatorname{Ref}[22]$ & Parallel & 76 & 2 & 10 & $3.5(-9 \%)$ & $155(0 \%)$ & $278(-33 \%)$ & 129 (-35\%) & $17(4 \%)$ & 17 (10\%) & $82(9 \%)$ & 129 (16\%) \\
\hline $\operatorname{Ref}[25]$ & Parallel & 190 & 2 & 12 & 3.9 (-9\%) & $151(-4 \%)$ & $284(-29 \%)$ & $142(-32 \%)$ & $18(5 \%)$ & 20 (19\%) & $98(3 \%)$ & 137 (19\%) \\
\hline $\operatorname{Ref}[28]$ & Parallel & 19 & 2 & 12 & $3.1(-16 \%)$ & $178(-4 \%)$ & $483(-\mathbf{2 4 \% )}$ & $198(-23 \%)$ & $17(-30 \%)$ & $18(2 \%)$ & $73(0 \%)$ & $95(-3 \%)$ \\
\hline $\operatorname{Ref}[19]$ & Crossover & 21 & 2.4 & 5 & $4.2(-\mathbf{1 2} \%)$ & $123(-\mathbf{9 \%})$ & $209(-\mathbf{2 8 \%})$ & $126(-\mathbf{2 8 \%})$ & 45 (11\%) & 18 (14\%) & 74 (15\%) & 175 (16\%) \\
\hline $\operatorname{Ref}[29]$ & Crossover & 11 & 3 & 6 & $3.8(-\mathbf{9 \%})$ & $94(-10 \%)$ & $241(-43 \%)$ & $110(-\mathbf{4 2} \%)$ & 31 (13\%) & 32 (10\%) & 109 (12\%) & 185 (14\%) \\
\hline $\operatorname{Ref}[21]$ & Parallel & 153 & 3 & 26 & $4.1(-\mathbf{1 1} \%)$ & $120(-8 \%)$ & 316 (-39\%) & $152(-\mathbf{1 8 \%})$ & $34(2 \%)$ & 18 (34\%) & 71 (11\%) & $176(\mathbf{2 0 \% )}$ \\
\hline $\operatorname{Ref}[20]$ & Crossover & 22 & 3 & 7 & $3.7(-\mathbf{1 7} \%)$ & 127 (-9\%) & $301(-41 \%)$ & $147(-\mathbf{2 2} \%)$ & $36(6 \%)$ & 15 (19\%) & 91 (11\%) & 170 (12\%) \\
\hline $\operatorname{Ref}[26]$ & Parallel & 67 & 3.4 & 6 & 3.7 (-9\%) & $122(-3 \%)^{1}$ & $346(-48 \%)^{1}$ & $151(-41 \%)^{1}$ & $33(13 \%)^{1}$ & 19 (21\%) & 111 (27\%) & 203 (10\%) \\
\hline $\operatorname{Ref}[17]$ & Parallel & 49 & 8.8 & 10 & $3.2(-\mathbf{1 7} \%)$ & $157(-2 \%)$ & $337(-62 \%)$ & $164(-48 \%)$ & 15 (14\%) & $23(20 \%)$ & 86 (15\%) & 130 (30\%) \\
\hline \multicolumn{13}{|c|}{ Dose-response studies } \\
\hline \multirow[t]{2}{*}{$\operatorname{Ref}[27]$} & Crossover & 15 & 0.8 & 9 & $4.4(-8 \%)$ & $102(4 \%)^{1}$ & $360(-\mathbf{2 8} \%)^{1}$ & $163(-24 \%)^{1}$ & $18(14 \%)^{1}$ & $20(-5 \%)^{1}$ & $69(1 \%)^{1}$ & $162(2 \%)^{1}$ \\
\hline & & & 2 & 6 & $4.5(-15 \%)$ & $102(-2 \%)^{1}$ & $347(-\mathbf{4 8 \%})^{1}$ & $158(-41 \%)^{1}$ & $20(-4 \%)^{1}$ & $22(10 \%)^{1}$ & $28(2 \%)^{1}$ & $160(16 \%)^{1}$ \\
\hline \multirow[t]{4}{*}{$\operatorname{Ref}[23]$} & Crossover & 22 & 0.8 & 4 & $4.4(-2 \%)$ & $141(1 \%)$ & $354(-20 \%)$ & $167(-39 \%)$ & $39(9 \%)$ & $21(3 \%)$ & $89(4 \%)$ & $133(13 \%)$ \\
\hline & & & 1.6 & & $"(-6 \%)$ & $"(-1 \%)$ & "(-35\%) & "(-21\%) & "(14\%) & "(18\%) & "(6\%) & "(18\%) \\
\hline & & & 2.3 & & "(-10\%) & $"(1 \%)$ & "(-35\%) & "(-34\%) & $"(21 \%)$ & $"(22 \%)$ & $"(7 \%)$ & "(19\%) \\
\hline & & & 3.1 & & "(-10\%) & "(1\%) & "(-39\%) & "(-32\%) & "(21\%) & "(12\%) & $"(8 \%)$ & "(19\%) \\
\hline
\end{tabular}

Plant stanols ( $\mathrm{g} / \mathrm{d}$ ) added as plant stanol ester (STAEST) to the test mayonnaise [26,27], test spread [18-25,28,29] or test spread and test oat-based drink [17].

LDL is given as mmol/l, and squalene- and non-cholesterol sterol/cholesterol-ratios as $10^{2} \times \mu \mathrm{mol} / \mathrm{mmol}$ of cholesterol.

${ }^{1}$ Calculated from the mean values given in the publication.

Bold: $p<0.05$ compared with control. 
cholesterol $\left(10^{2} \times \mu \mathrm{mol} / \mathrm{mmol}\right.$ of cholesterol), which was obtained from the same GLC run.

In the absolute metabolic studies, the participants took a capsule containing $200 \mathrm{mg}$ of $\mathrm{Cr}_{2} \mathrm{O}_{3},{ }^{3} \mathrm{H}$-sitostanol, and ${ }^{14} \mathrm{C}$-cholesterol three times a day with each major meal for a week. During the last three days, stools were collected and pooled for analysis of labels, neutral sterols, and bile acids. The sterols and bile acids were measured with GLC [31], using the recovery of $\mathrm{Cr}_{2} \mathrm{O}_{3}$ or labeled sitostanol for measurement of fecal flow. During the week, the participants kept a food diary so that energy, fat and cholesterol intakes could be quantified with the assistance of a computerized program [32].

\section{Statistics}

All statistical analyses were performed with the SPSS for Windows 19.0 statistics program (SPSS, Chicago, IL, USA).

Since the separate studies differed in their design (Table 1), the relative changes from the control values were recalculated from original data except in two studies $[26,27]$, in which the relative changes were calculated from the mean values given in the publications. The normal distribution of variables was confirmed before further statistical analyses. When detecting the relationships between the plant stanol dose and serum LDL cholesterol and non-cholesterol sterols, nine studies with hypercholesterolemic subjects [17-25] were included into the further statistical analyses. Curve equations were calculated by analysis of curve estimation and ANCOVA with the study as a covariate. Pearson correlation coefficients were also calculated. In addition, when detecting the validity, i.e. the associations between the simultaneous measurements of the serum noncholesterol sterols and absolute cholesterol synthesis and absorption, the Pearson or Spearman correlation coefficients were calculated from the studies in which the data was available $[20,27,29]$. A P value of $<0.05$ was considered statistically significant.

\section{Results}

\section{Serum non-cholesterol sterols as biomarkers of} cholesterol metabolism

In three studies $(\mathrm{n}=39)[20,27,29]$, cholesterol metabolism was evaluated with simultaneous measurements of fractional cholesterol absorption, cholesterol synthesis, and serum non-cholesterol sterols. During both the control and STAEST periods, serum cholestanol, campesterol and sitosterol concentrations (Table 2) and ratios to cholesterol, shown for cholestanol/cholesterol- and sitosterol/ cholesterol-ratios in Figure 1 (Panels A and B), correlated with fractional cholesterol absorption. Similarly, during the control and STAEST periods, serum cholestenol, desmosterol, and lathosterol concentrations (Table 2) and
Table 2 Correlation coefficients between serum non-cholesterol sterol concentrations and the absolute measurements of cholesterol metabolism

\begin{tabular}{lcl}
\hline $\begin{array}{l}\text { Serum squalene and } \\
\text { non-cholesterol } \\
\text { sterols, } \boldsymbol{\mu g} / \mathbf{d l}\end{array}$ & $\begin{array}{c}\text { During } \\
\text { control } \\
\text { period }\end{array}$ & $\begin{array}{l}\text { During plant stanol } \\
\text { ester intervention }\end{array}$ \\
\hline Squalene & $\begin{array}{c}\text { Cholesterol synthesis, } \\
\mathbf{m g} / \mathbf{k g} / \mathbf{d}\end{array}$ \\
Cholestenol & -0.133 & -0.053 \\
Desmosterol & $0.515^{* *}$ & $0.592^{* *}$ \\
Lathosterol & $0.325^{*}$ & $0.425^{* *}$ \\
& $0.366^{*}$ & $0.378^{*}$ \\
Cholestanol & Fractional cholesterol \\
absorption, \% & \\
Campesterol & $0.627^{* * *}$ & $0.558^{* * *}$ \\
Sitosterol & $0.394^{*}$ & $0.411^{* *}$ \\
\hline
\end{tabular}

The results from three studies $[20,27,29]$ were combined.

${ }^{*} \mathrm{p}<0.05 ;{ }^{* *} \mathrm{p}<0.01 ;{ }^{* * *} \mathrm{p}<0.001$.

$\mathrm{N}=39$.

ratios to cholesterol (shown for cholestenol/cholesterolratio in Figure 1 Panel C) correlated with cholesterol synthesis. Serum squalene concentration or squalene/ cholesterol-ratio did not correlate with cholesterol synthesis. The sitosterol/lathosterol-ratio correlated with fractional cholesterol absorption during the control $(r=0.589$, $\mathrm{p}<0.001)$ and STAEST periods $(\mathrm{r}=0.662, \mathrm{p}<0.001)$, and the corresponding values for cholesterol synthesis were $\mathrm{r}=-0.532, \mathrm{p}<0.001$ and $\mathrm{r}=-0.512, \mathrm{p}<0.001$.

\section{Relative changes in LDL cholesterol and serum} non-cholesterol sterol levels

In studies involving daily plant stanol intake $\geq 1.6 \mathrm{~g}$, the LDL cholesterol concentration was significantly reduced (Table 1). Depending on the dose, the LDL cholesterol level was reduced by $6 \%$ (plant stanols $1.6 \mathrm{~g} / \mathrm{d}$ ) up to $17 \%$ (plant stanols $8.8 \mathrm{~g} / \mathrm{d}$ ). The extent of the reduction in LDL cholesterol correlated with the plant stanol dose $(\mathrm{r}=0.686, \mathrm{p}=0.014)$ (Figure 2 Panel A).

When compared to the controls, serum campesterol/ cholesterol-ratio and sitosterol/cholesterol-ratio were reduced in every study (Table 1). The reductions of plant sterol/cholesterol-ratios were dose-dependent as shown for the serum campesterol/cholesterol-ratio in Figure 2 Panel B $(r=-0.919, p<0.001)$. On the contrary, serum cholestanol/cholesterol-ratio was reduced only in 5/17 trials (Table 1 ), and the reductions were not associated with the plant stanol dose.

Regarding the serum cholesterol precursors, STAEST consumption increased serum squalene/cholesterol-ratio in $1 / 17$ trials, the cholestenol/cholesterol-ratio in $9 / 17$ trials, the desmosterol/cholesterol-ratio in $8 / 17$ trials, and the lathosterol/cholesterol-ratio in a clear majority 

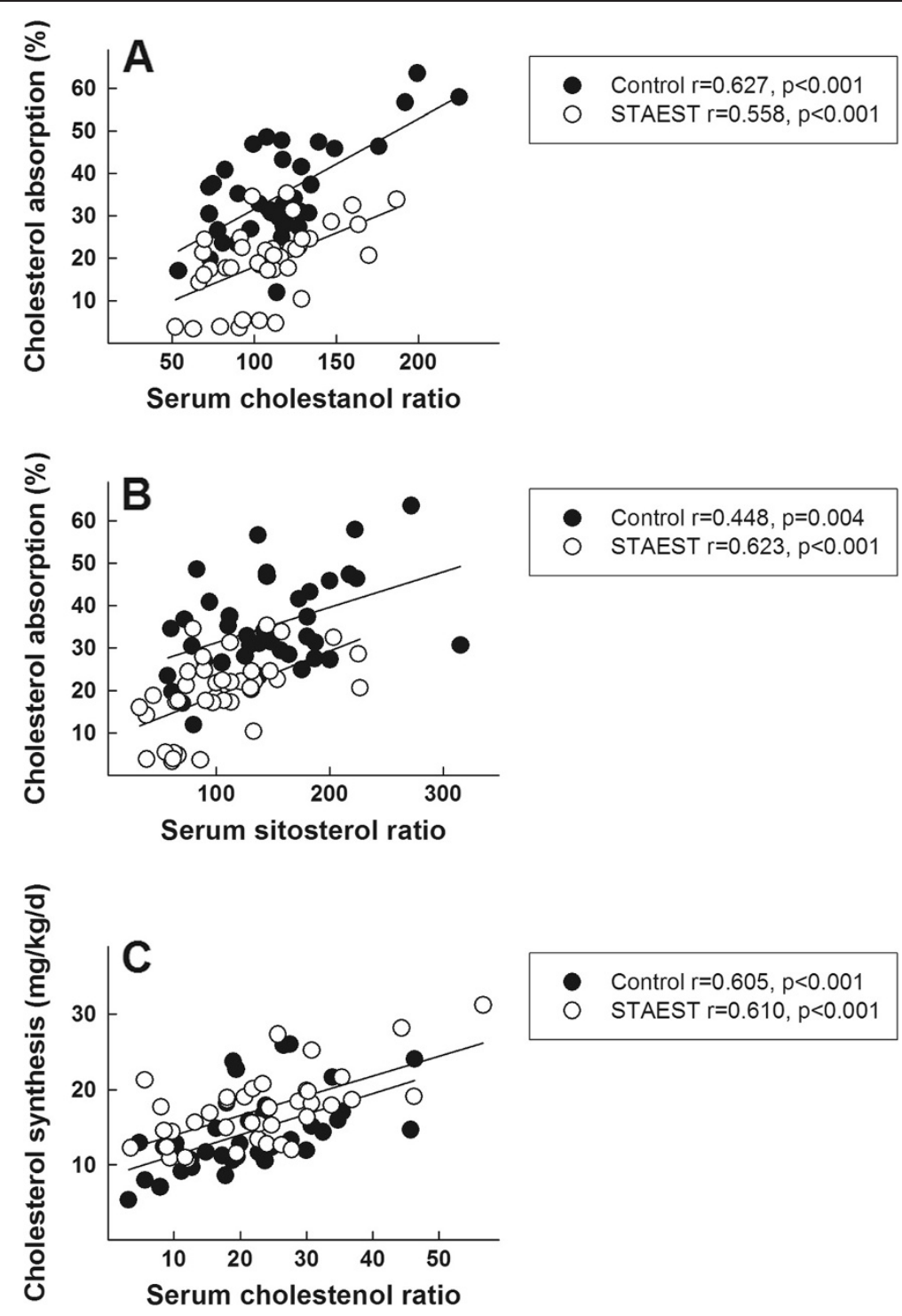

Figure 1 Cholesterol absorption and synthesis and serum biomarkers. Three studies $[20,27,29]$ combined, $n=39$. Panel A: Fractional cholesterol absorption (\%) and serum cholestanol/cholesterol- ratio $\left(10^{2} \times \mu \mathrm{mol} / \mathrm{mmol}\right.$ of cholesterol) in 39 subjects during the control (closed circles) and plant stanol ester (STAEST) (open circles) intervention periods. The results from three studies $[20,27,29]$ were combined. Panel B: Fractional cholesterol absorption (\%) and serum sitosterol/cholesterol- ratio $\left(10^{2} \times \mu \mathrm{mol} / \mathrm{mmol}\right.$ of cholesterol) in 39 subjects during the control (closed circles) and plant stanol ester (STAEST) (open circles) intervention periods. The results from three studies $[20,27,29]$ were combined. Panel C: Cholesterol synthesis $(\mathrm{mg} / \mathrm{kg} / \mathrm{d})$ and serum cholestenol/cholesterol- ratio $\left(10^{2} \times \mu \mathrm{mol} / \mathrm{mmol}\right.$ of cholesterol) in 39 subjects during the control (open circles) and plant stanol ester (STAEST) (open circles) intervention periods.

in $13 / 17$ of the trials (Table 1 ). The increase in the precursor sterol to cholesterol ratios varied from 7 to $34 \%$, respectively, but there was extensive variation between different studies even with the same plant stanol dose. In two studies $[17,28]$, all of the precursors remained unchanged.

\section{Discussion}

The new results emerging from these analyses demonstrate that during plant stanol consumption, serum noncholesterol sterol/cholesterol- ratios reflect the fractional absorption and whole-body synthesis of cholesterol. In addition, serum absorption/synthesis marker ratios were found to be valid markers of cholesterol metabolism during plant stanol intervention. Second, serum levels of plant sterols were dose-dependently reduced by plant stanols. The serum cholestanol level was reduced less frequently than the serum plant sterol levels during consumption of STAEST. The cholesterol precursor sterols, cholestenol, desmosterol and lathosterol, were not increased similarly or were not increased at all in some studies emphasizing the importance of adopting more 


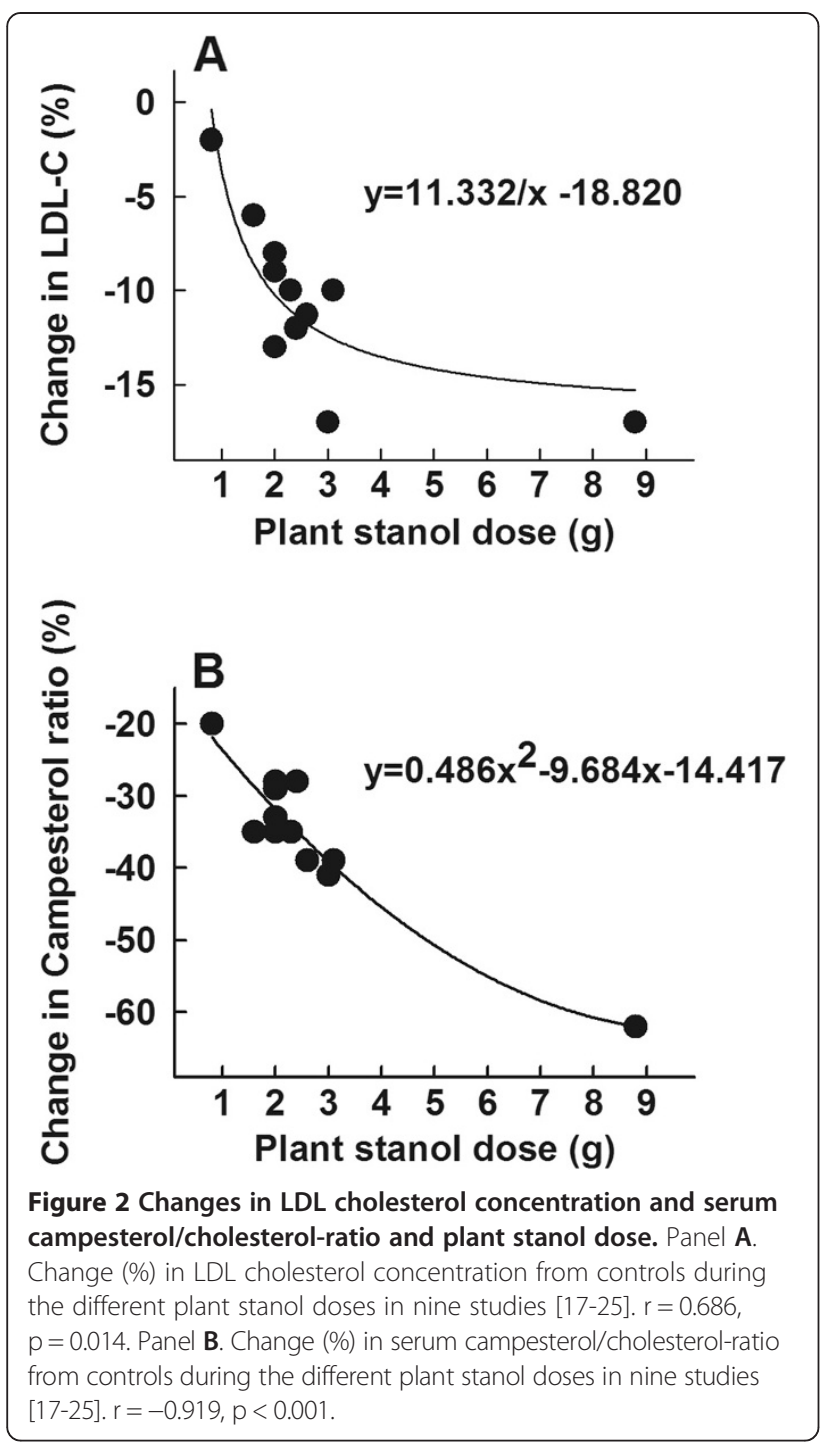

than one surrogate serum marker. The serum squalene level was not related to cholesterol metabolism.

The study population contained all randomized controlled plant stanol interventions in adults gathered from PubMed, in which at least two serum synthesis markers, two serum plant sterols, and serum cholestanol were analysed. It turned out that the requirement for the noncholesterol sterols excluded other than our own studies. In fact, 4 more studies could be retrieved from PubMed containing serum lathosterol and plant sterol quantifications, but not the other non-cholesterol sterols.

If one adopts surrogate serum markers, there is always the caveat that their validity should not be considered as self-evident [8]. In situations when there is interference with the homeostasis of cholesterol or the metabolism of an individual marker, the serum value of the marker/s no longer reflects cholesterol metabolism. Accordingly, the metabolism of both cholesterol and the individual marker need to be taken into consideration when interpreting the data. A classic example of potential misinterpretation is the fact that plant sterols cannot be used as cholesterol absorption markers at the same time when the subjects are consuming plant sterol-added products. Similarly, when dietary intake of cholesterol was increased by adding daily egg consumption, there was an elevation in the serum lathosterol concentration, but this no longer reflected cholesterol synthesis but instead the increased intake of lathosterol present in the egg yolk [11]. Even under baseline situations, the relative serum markers may not reflect cholesterol metabolism. In vegetarians, cholesterol synthesis is known to be elevated as compared with control subjects, but there was no increase in the concentrations of the serum cholesterol precursors [33].

In the present study, all serum cholesterol precursors were unchanged in two studies. The subjects in one of these studies were type 1 diabetics, and the precursor ratios to cholesterol varied from $-30 \%$ to $+2 \%$. Why in type 1 diabetes cholesterol synthesis seems not to be activated remains open and warrants further investigation. Regarding the second study, the cholesterol precursors were increased from $14 \%$ to $30 \%$, but the increment did not reach significance.

Cholestanol is a saturated derivative of cholesterol produced by the liver. Its synthesis involves mainly a rate-limiting oxidation pathway, but a smaller fraction is also synthesized as a by-product of bile acid production [34]. The dietary intake of cholestanol is minimal, less than $2 \mathrm{mg} / \mathrm{d}$ [9], but if biliary secretion is impaired such as in cholestasis, then serum cholestanol values rapidly increase and no longer reflect the absorption efficiency of cholesterol [35]. Even though the serum cholestanol concentration and the cholestanol/cholesterol-ratio correlated with fractional cholesterol absorption during STAEST, in the individual studies the cholestanol/cholesterol-ratio was less frequently reduced than the serum plant sterol/cholesterol-ratios.

In the present analysis, the relative LDL cholesterol reduction varied from 6 to $17 \%$ depending on the plant stanol dose used in the different studies. Similarly, the relative reduction for campesterol/cholesterol-ratio varied from 35 to $62 \%$. One can calculate that a $2 \mathrm{~g}$ plant stanol dose can achieve about a $10 \%$ reduction in the LDL cholesterol concentration and a $32 \%$ decrease in the serum campesterol/cholesterol-ratio (Figure 2). Accordingly, the change in serum campesterol/cholesterol-ratio can also be utilized as an indicator of the compliance of the STAEST intake. An earlier study demonstrated that when LDL cholesterol was lowered by $10 \%$ with plant stanols, fractional cholesterol absorption was reduced by $45 \%$ and the serum campesterol/cholesterol-ratio by $34 \%(\mathrm{p}<0.05$ for all $)$ [36], which is the 
same magnitude estimated in the present study. These values suggest that approximately a four-fold inhibition in cholesterol absorption efficiency is needed to achieve a unit decrease in the LDL cholesterol concentration.

\section{Conclusions}

In conclusion, serum non-cholesterol sterols are valid markers of cholesterol absorption and synthesis during cholesterol absorption inhibition with plant stanol ester. Serum levels of non-cholesterol sterols did not change consistently in the individual studies emphasizing the importance of utilizing more than one surrogate serum marker. Serum plant sterols decrease dose-dependently after consumption of plant stanols suggesting that the higher the plant stanol dose, the more cholesterol absorption will be inhibited and the more efficiently the LDL cholesterol levels will be reduced.

\section{Abbreviations}

GLC: Gas-liquid chromatography; STAEST: Plant stanol ester.

\section{Competing interests}

HG has received research funding from Raisio Group, Finland. MH and PS declare no competing interests.

\section{Authors' contributions}

$\mathrm{MH}$ collected the data, performed the statistical analysis and drafted the first version of the manuscript. $\mathrm{MH}, \mathrm{PS}$, and $\mathrm{HG}$ critically revised the manuscript and approved the final version.

\section{Acknowledgements}

The study was supported by Raisio Nutrition Ltd (CL2009_019).

This study is dedicated to the memory of Professor Tatu A. Miettinen.

\section{Author details}

${ }^{1}$ Institute of Public Health and Clinical Nutrition, Department of Clinical Nutrition, University of Eastern Finland, Kuopio, Finland. ${ }^{2}$ Heart and Lung Center, Helsinki University Hospital, Helsinki, Finland. ${ }^{3}$ Department of Medicine, Division of Internal Medicine, University of Helsinki, Helsinki, Finland, P.O. BOX 700 FIN-00029 HUS, Finland.

Received: 12 March 2014 Accepted: 22 April 2014

Published: 27 April 2014

\section{References}

1. Pollak OJ: Reduction of blood cholesterol in man. Circulation 1953 VII:702-706

2. Heinemann T, Leiss O, von Bergmann K: Effect of low-dose sitostanol on serum cholesterol in patients with hypercholesterolemia. Atherosclerosis 1986, 61:219-223.

3. Grundy SM, Ahrens EH Jr, Davignon J: The interaction of cholesterol absorption and cholesterol synthesis in man. J Lipid Res 1969, 10:304-315.

4. Heinemann T, Kullak-Ublick G-A, Pietruck B, von Bergmann K: Mechanisms of action of plant sterols on inhibition of cholesterol absorption. Eur J Clin Pharmacol 1991, 40(Suppl. 1):S59-S63.

5. Miettinen TA: Serum squalene and methyl sterols as indicators of cholesterol synthesis in vivo. Life Sci 1969, 8:713-721.

6. Miettinen TA, Tilvis RS, Kesäniemi YA: Serum plant sterols and cholesterol precursors reflect cholesterol absorption and synthesis in volunteers of a randomly selected male population. Am J Epidemiol 1990, 131:20-31.

7. Simonen $P$, Gylling $H$, Miettinen TA: The validity of serum squalene and non-cholesterol sterols as surrogate markers of cholesterol synthesis and absorption in type 2 diabetes. Atherosclerosis 2008, 197:883-888.

8. Miettinen TA, Gylling H, Nissinen MJ: The role of serum non-cholesterol sterols as surrogate markers of absolute cholesterol synthesis and absorption. Nutr Metab Cardiovasc Dis 2011, 21:765-769.
9. Miettinen TA, Tilvis RS, Kesäniemi YA: Serum cholestanol and plant sterol levels in relation to cholesterol metabolism in middle-aged men. Metabolism 1989, 38:136-140.

10. Kempen HJ, Glatz JF, Gevers Leuven JA, van der Voort HA, Katan MB: Serum lathosterol concentration is an indicator of whole-body cholesterol synthesis in humans. J Lipid Res 1988, 29:1149-1155

11. Duane WC: Serum lathosterol levels in human subjects reflect changes in whole body cholesterol synthesis induced by lovastatin but not dietary cholesterol. J Lipid Res 1995, 36:343-348.

12. Björkhem I, Miettinen T, Reihnér E, Ewerth $\mathrm{S}$, Angelin B, Einarsson K: Correlation between serum levels of some cholesterol precursors and activity of HMG-CoA reductase in human liver. J Lipid Res 1987, 28:1137-1143.

13. Crouse JR, Grundy SM: Evaluation of a continuous isotope feeding method for measurement of cholesterol absorption in man. J Lipid Res 1978, 19:967-971.

14. Racette SB, Lin X, Lefevre M, Anderson Spearie C, Most MM, Ma L, Ostlund RE Jr: Dose effects of dietary phytosterols on cholesterol metabolism: a controlled feeding study. Am J Clin Nutr 2010, 91:32-38.

15. Jakulj L, Mohammed H, van Dijk TH, Boer T, Turner S, Groen AK, Vissers MN Stroes ES: Plasma plant sterols serve as poor markers of cholesterol absorption in man. J Lipid Res 2013, 54:1144-1150.

16. Grundy SM: Plasma noncholesterol sterols as indicators of cholesterol absorption. J Lipid Res 2013, 54:873-875.

17. Gylling $H$, Hallikainen M, Nissinen MJ, Simonen P, Miettinen TA: Very high plant stanol intake and serum plant stanols and non-cholesterol sterols. Eur J Nutr 2010, 49:111-117.

18. Gylling H, Hallikainen M, Raitakari OT, Laakso M, Vartiainen E, Salo P, Korpelainen $V$, Sundvall J, Miettinen TA: Long-term consumption of plant stanol and sterol esters, vascular function and genetic regulation. Brit J Nutr 2009, 101:1688-1695

19. Gylling $H$, Miettinen $\mathrm{T}$ : Cholesterol reduction by different plant stanol mixtures and with variable fat intake. Metabolism 1999, 48:575-580.

20. Gylling H, Radhakrishnan R, Miettinen TA: Reduction of serum cholesterol in postmenopausal women with previous myocardial infarction and cholesterol malabsorption induced by dietary sitostanol ester margarine. Women and dietary sitostanol. Circulation 1997, 96:4226-4231.

21. Gylling H, Puska P, Vartiainen E, Miettinen TA: Serum sterols during stanol ester feeding in a mildly hypercholesterolemic population. J Lipid Res 1999, 40:593-600.

22. Hallikainen M, Lyyra-Laitinen T, Laitinen T, Ågren JJ, Pihlajamäki J, Rauramaa $\mathrm{R}$, Miettinen TA, Gylling H: Endothelial function in hypercholesterolemic subjects: Effects of plant stanol and sterol esters. Atherosclerosis 2006, 188:425-432.

23. Hallikainen MA, Sarkkinen ES, Uusitupa MIJ: Plant stanol esters affect serum cholesterol concentrations of hypercholesterolemic men and women in a dose-dependent manner. J Nutr 2000, 130:767-776.

24. Hallikainen MA, Sarkkinen ES, Gylling H, Erkkilä AT, Uusitupa MI: Comparison of the effects of plant sterol ester and plant stanol ester-enriched margarines in lowering serum cholesterol concentrations in hypercholesterolaemic subjects on a low-fat diet. Eur J Clin Nutr 2000, 54:715-725

25. Raitakari OT, Salo P, Gylling H, Miettinen TA: Plant stanol ester consumption and arterial elasticity and endothelial function. Brit J Nutr 2008, 100:603-608

26. Vanhanen HT, Blomqvist S, Ehnholm C, Hyvönen M, Jauhiainen M, Torstila I, Miettinen TA: Serum cholesterol, cholesterol precursors, and plant sterols in hypercholesterolemic subjects with different apoE phenotypes during dietary sitostanol ester treatment. J Lipid Res 1993, 34:1535-1544.

27. Vanhanen HT, Kajander J, Lehtovirta H, Miettinen TA: Serum levels, absorption efficiency, faecal elimination and synthesis of cholesterol during increasing doses of dietary sitostanol esters in hypercholesterolaemic subjects. Clin Sci 1994, 87:61-67.

28. Hallikainen M, Lyyra-Laitinen T, Laitinen T, Moilanen L, Miettinen TA, Gylling $\mathrm{H}$ : Effects of plant stanol esters on serum cholesterol concentrations, relative markers of cholesterol metabolism and endothelial function in type 1 diabetes. Atherosclerosis 2008, 199:432-439.

29. Gylling $H$, Miettinen TA: Serum cholesterol and cholesterol and lipoprotein metabolism in hypercholesterolaemic NIDDM patients before and during sitostanol ester-margarine treatment. Diabetologia 1994, 37:773-780 
30. Miettinen TA: Cholesterol metabolism during ketoconazole treatment in man. J Lipid Res 1988, 29:43-51.

31. Miettinen TA: Gas-liquid chromatographic determination of fecal neutral sterols using a capillary column. Clin Chim Acta 1982, 124:245-248.

32. Knuts L-R, Rastas M, Haapala P: Micro-Nutrica. Version 1.0. Helsinki, Finland: Social Insurance Institution; 1991.

33. Vuoristo M, Miettinen TA: Absorption, metabolism, and serum concentrations of cholesterol in vegetarians: effects of cholesterol feeding. Am J Clin Nutr 1994, 59:1325-1331.

34. Björkhem I, Boberg KM, Leitersdorf E: Inborn errors in bile acid biosynthesis and storage of sterols other than cholesterol. In The Metabolic and Molecular Bases of Inherited Disease. Edited by Scriver CS, Beaudet AL, Sly WS, Valle D. New York: McGraw-Hill; 2001:2961-2988.

35. Gylling $H$, Vuoristo $M$, Färkkila M, Miettinen TA: The metabolism of cholestanol in primary biliary cirrhosis. J Hepatol 1996, 24:444-451.

36. Miettinen TA, Gylling H: Non-nutritive bioactive constituents of plants: phytosterols. Internat J Vit Nutr Res 2003, 73:127-134.

doi:10.1186/1476-511X-13-72

Cite this article as: Hallikainen et al: Cholesterol metabolism and serum non-cholesterol sterols: summary of 13 plant stanol ester interventions. Lipids in Health and Disease 2014 13:72.

\section{Submit your next manuscript to BioMed Central and take full advantage of:}

- Convenient online submission

- Thorough peer review

- No space constraints or color figure charges

- Immediate publication on acceptance

- Inclusion in PubMed, CAS, Scopus and Google Scholar

- Research which is freely available for redistribution 